Research Paper

\title{
Capable Infection of Hepatitis B Virus in Diffuse Large B-cell Lymphoma
}

\author{
Yanchun Wang1, 2\#, Huijie Wang2, 4 \#, Shaokun Pan³, Tao Hu¹, Jiabin Shen'1, Hui Zheng1, 2, Suhong Xie ${ }^{1,2}$, \\ Youhua $\mathrm{Xie}^{3}$, Renquan $\mathrm{Lu}^{1,2}$, Lin Guo ${ }^{1,2}{ }^{凶}$ \\ 1. Department of Clinical Laboratory, Fudan University Shanghai Cancer Center, Shanghai, China \\ 2. Department of Oncology, Shanghai Medical College, Fudan University, Shanghai, China \\ 3. Department of Pathogen Biology, Shanghai Medical College, Fudan University, Shanghai, China \\ 4. Department of Oncology, Fudan University Shanghai Cancer Center, Shanghai, China \\ \#These authors contributed equally to this work. \\ $\triangle$ Corresponding author: Lin Guo, Department of Clinical Laboratory, Fudan University Shanghai Cancer Center, No. 270, Dong'an Road, Shanghai 200032, \\ China. Tel: +86-21-64175590; Fax: +86-21-64175590-82204; E-mail: guolin500@hotmail.com. Renquan Lu, lurenquan@126.com. \\ () Ivyspring International Publisher. This is an open access article distributed under the terms of the Creative Commons Attribution (CC BY-NC) license \\ (https://creativecommons.org/licenses/by-nc/4.0/). See http://ivyspring.com/terms for full terms and conditions.
}

Received: 2017.12.15; Accepted: 2018.02.08; Published: 2018.04.12

\begin{abstract}
Background: Diffuse large B-cell lymphoma (DLBCL) is the most common pathological type of non-Hodgkin lymphoma (NHL). It is strongly correlated to the host immunity and infection status.

Aim: This study tested the hypothesis that hepatitis B virus (HBV) infection is also associated with DLBCL.

Methods: Clinical analysis of the correlation between DLBCL and HBV infection, detection of HBV in situ of DLBCL tissue, and biological experiments that determined whether HBV infects $B$ lymphocytes were conducted.

Results: Our long-term clinical data showed that the positive rate of serum HBV was significantly increased in DLBCL patients (23.6\%) compared to that in the general Chinese population $(7.2 \%$, $P<0.001)$, especially in advanced stage lymphoma patients $(P=0.003)$. In addition, HBV could infect $B$ lymphocytes in vitro and the HBV antigen and nucleic acid could be detected intracellularly. Hepatitis $B \times$ protein $(\mathrm{HBx})$ was also strongly expressed in tissues from DLBCL patients that were serum $\mathrm{HBV}$ surface antigen $(\mathrm{HBsAg})$ positive. These patients responded less well to therapy with an odds ratio (OR) of 3.04 .

Conclusions: $\mathrm{HBV}$ can infect $B$ lymphocytes. It might be related to the development of DLBCL and may also impact the efficacy of treatment.
\end{abstract}

Key words: Diffuse large B cell lymphoma; hepatitis B virus; infection

\section{Introduction}

Non-Hodgkin lymphoma (NHL) as one of the most common cancers accounts for $4-5 \%$ of all cancers [1]. Diffuse large B-cell lymphoma (DLBCL) is the top pathological type occupying $30-60 \%$ of NHL [2]. The cause of this disease is strongly correlated with the host immunity and infection status. All currently found tumor viruses can be related to the tumorigenesis and progression of NHL. For example, the Epstein-Barr virus, which has been shown to be associated with various cancers, including Burkitt's lymphoma, can infect B lymphocytes via the CD21 receptor on B-cell surface [3]. Furthermore, the positive rate of hepatitis $\mathrm{C}$ virus antibody in B-cell NHL patients was significantly higher than that in healthy controls, suggesting a relationship between hepatitis C virus and B-cell NHL [4]. Therefore, we speculated that hepatitis $B$ virus (HBV) may also be associated with NHL.

HBV infection is a worldwide health problem with an estimated 257 million carriers of hepatitis B 
surface antigen (HBsAg) (WHO, 2017). HBV prevalence is highest in the endemic area of WHO Western Pacific Region, and the percentage of carriers of HBsAg is estimated to be $7.2 \%$ in China [5]. Although there are few clinical trials to show a higher prevalence of HBsAg in DLBCL patients [6], there have been no large analyses of $\mathrm{HBV}$ that report the relationship to DLBCL severity, staging, or prognosis. At present, the effect of the HBV positivity rate of serum on the prognosis of DLBCL remains unknown $[7,8]$.

In patients with DLBCL that are positive for hepatitis $\mathrm{B}$ core antibody $(\mathrm{HBc} \mathrm{Ab})$ and who are being treated with CD20-targeted antibodies, the ability of B-cells to secrete HBV-specific antibodies is impaired, which potentially activates replication of previously infected HBV and particularly increases the risk of serum HBsAg conversion [9, 10]. However, a significantly higher proportion of $\mathrm{HBV}$ infection in patients before DLBCL treatment indicates that HBV infection in DLBCL patients is not correlated with the use of targeted chemotherapy drugs. In addition, human peripheral blood mononuclear cells (PBMCs) may habor HBV [11], suggesting that HBV infects antigen presenting lymphocytes [12], which indicates that lymphoma progression may be caused by the virus infection.

In order to test the hypothesis that HBV infection is correlated with DLBCL, interpretationally in part from $\mathrm{HBV}$ directly infecting $B$ lymphocytes, a clinical analysis of the correlation between DLBCL and HBV infection was carried out, and whether HBV infects B lymphocytes in vitro was also determined. This project will shed light on the etiology of the novel interpretation to DLBCL by $\mathrm{HBV}$ infection, and facilitate the basis for new strategies to the treatment and prevention of this disease.

\section{Materials and methods}

\section{Serum samples}

Sera from NHL patients in the Shanghai Cancer Center from 2009 to 2017 January were included in this study. HBsAg, hepatitis B surface antibody (HBsAb), $\mathrm{HBcAb}$, hepatitis $\mathrm{B}$ e antigen (HBeAg), and hepatitis $B$ e antibody ( $\mathrm{HBe} A b)$ in serum were tested by commercial electro-chemiluminescence assays (Abbott i2000, Abbott Laboratories, USA). HBV DNA was analyzed by quantitative polymerase chain reaction (PCR) using a commercial probe (Shanghai Kehua Bio-engineering, China) as per the manufacturer's instructions.

\section{Cell culture}

Pfeiffer cells, originally from the American Type Culture Collection, were cultured in RPMI 1640
(Gibco, USA) containing 10\% FBS and 1\% penicillin/streptomycin maintained at $37^{\circ} \mathrm{C}$ in a humidified $5 \% \mathrm{CO}_{2}$ incubator. Cells were passaged every three days. PBMCs were separated from the uncoagulated blood by a density gradient centrifugation method using Ficoll Histopaque in a 15 $\mathrm{mL}$ centrifuge tube that was centrifuged for $20 \mathrm{~min}$ at $750 \times g$ in a swinging bucket without braking. The PBMCs in the interphase were aspirated and washed twice with sterile PBS by centrifugation at $300 \times g$ for $10 \mathrm{~min}$. The pellet was resuspended by complete medium and cultured like the Pfeiffer cells.

\section{HBV infection in vitro}

Cells were infected with HBV at a multiplicity of infection (MOI) of 10. To synchronize the stage of infection, the plates were centrifuged at $300 \times g$ for 10 min and then co-incubated in a humidified $5 \% \mathrm{CO}_{2}$ incubator for $24 \mathrm{~h}$. Subsequently, the cells were washed extensively with pre-cooled phosphatebuffered solution to stop phagocytosis and extracellular HBV was removed by centrifugation at $300 \times g$ for $10 \mathrm{~min}$ three times.

To detect the HBV infection, a confocal method was used in which $2 \times 10^{5}$ cells per well were incubated on $0.1 \%$ polylysine-treated slides in a 24 -well plate. After $1 \%$ paraformaldehyde fixation and $0.5 \%$ Triton X-100 permeabilization, cells were stained with a mouse anti-HBx primary antibody and TRITCconjugated anti-mouse IgG was used as the secondary antibody. Cells were nuclear stained with DAPI and were detected by confocal microscopy (Leica SP5).

\section{HBV DNA detection in infected cells}

HBV-infected cells were lysed for $10 \mathrm{~min}$ at $100^{\circ} \mathrm{C}$ in lysis buffer supplemented with proteinase $\mathrm{K}$ (200 $\mathrm{\mu g} / \mathrm{mL})$, followed by centrifugal column extraction (Da'an, Zhong Shan University, China). DNA from DLBCL tissue was extracted by supporting magnetic kit (The EmerTher Company, China). It was detected by PCR using a protocol as previously described with modifications [13].

In particular, primer pairs for detection of full length transcripts (3.5kb-2270F: GAGTGTGGATTCG CACTCC and 3.5kb-2392R: GAGGCGAGGGAGTTC TTCT) and total transcripts (t-1805F: TCACCAGCA CCATGCAAC and t-1896R: AAGCCACCCAAGGCA CAG), were validated and used for PCR, which was performed with the Ex Taq kit (Takara Bio) on a BioRad T100 instrument. Amplification of the $123 \mathrm{bp}$ $3.5 \mathrm{~kb}-\mathrm{DNA}$ and $92 \mathrm{bp}$ total-DNA products was conducted by routine denaturation, annealing $\left(60^{\circ} \mathrm{C}\right)$ and elongation. The products were separated by electrophoresis and sequenced for verification. 


\section{Immunohistochemistry}

Primary antibodies against hepatitis B core $(\mathrm{HBc})$, surface $(\mathrm{HBs})$, and $\mathrm{x}(\mathrm{HBx})$ antigens, respectively, were used for immunohistochemistry (IHC), following the standard protocol recommended [14]. Antigen expression was categorized by determining the immunoreactive score (IRS) as described previously [15]. Each spot was assigned an intensity score from 0 to 3 , and the proportion of tumor staining for that intensity was recorded in terms of $25 \%$ increments in the range $0-100$ (P0, P1-4), while less than $5 \%$ was recorded as zero. A final IRS (range 0-12) was obtained by adding the products of scores obtained for each intensity multiplied by the proportion of the area stained.

Table 1. Prevalence of serum HBsAg of lymphoma patients.

\begin{tabular}{lll}
\hline Lymphoma type (Number of patients) & HBsAg prevalence \% $(n)$ & $P$ value \\
\hline All B-NHLs $(n=747)$ & $21.6(161)$ & $<0.001$ \\
DLBCL $(n=508)$ & $23.6(120)$ & $<0.001$ \\
FL $(n=107)$ & $22.4(24)$ & $<0.001$ \\
Other B-NHLs $(n=132)$ & $12.9(17)$ & $\mathbf{0 . 0 1 2}$ \\
All T-NHLs $(n=338)$ & $8.6(29)$ & 0.328 \\
NK/T $(n=234)$ & $8.1(19)$ & 0.587 \\
PTCL $(n=72)$ & $9.7(7)$ & 0.408 \\
Other T-NHLs $(n=32)$ & $9.4(3)$ & $0.500^{a}$ \\
Unclassified NHL $(n=7)$ & $0(0)$ & $1.000^{a}$
\end{tabular}

$\mathrm{HBsAg}$ prevalence of respective lymphoma type was compared with the prevalence $(7.2 \%, 5888 / 81775)$ of Chinese population by $\chi^{2}$ tests.

a $P$ values were given by Fisher's exact test for expected count less than 5 . FL: follicular lymphoma, T-NHL: T-cell non-Hodgkin lymphoma, PTCL: peripheral T-cell lymphoma, NK/T: NK/T cell lymphoma.

Table 2. The positive rate of serum $\mathrm{HBsAg}$ in various $\mathrm{DLBCL}$ stage.

\begin{tabular}{lll}
\hline DLBCL Stage (Number of patients) & Positive rate of HBsAg \% (n) & $P$ value \\
\hline Early Stage, I+II $(n=289)$ & $18.7(54)$ & $\mathbf{0 . 0 0 3}$ \\
Advanced Stage, III+IV $(n=219)$ & $30.1(66)$ & \\
& & \\
Stage I $(n=117)$ & $21.4(25)$ & \\
Stage II $(n=172)$ & $16.9(29)$ & \\
Stage III $(n=98)$ & $33.7(33)$ & \\
Stage IV $(n=121)$ & $27.3(33)$ & \\
\hline
\end{tabular}

The difference of serum HBsAg positivity between early and advanced DLBCL stage was compared by $\chi^{2}$ test. Tendency difference among serum HBsAg and DLBCL stage was additionally compared by linear trend $x^{2}$ test.

\section{Statistical analysis}

Statistical analysis was performed using SPSS version 20.0 (IBM Corporation, USA), and figures were generated using GraphPad Prism software version 5.0. The data are expressed as the means \pm standard deviation. The mean values obtained from the experiments were compared using one-way ANOVA analysis with post-hoc test. A $P$-value of less than 0.05 was considered significant.

\section{Results}

\section{HBV infection is clinically related to the development of DLBCL}

In this study, 1092 NHL patients were included in the statistical analysis. DLBCL was the dominant lymphoma responsible for $68.0 \%(508 / 747)$ of B-cell NHL and $46.5 \%(508 / 1092)$ of NHL. In total, there were $190 \mathrm{HBsAg}$-positive serum samples. The rate of HBsAg-positive serum was highest in DLBCL patients $(23.6 \%$, Table 1$)$. In $97 \%(116 / 120)$ of the HBsAg-positive serum samples, serological markers against $\mathrm{HBV}$ of $\mathrm{HBcAb}$ were also detected. However, 222 of the 388 HBsAg-negative staff members also had $\mathrm{HBcAb}$. The significantly higher rate $(66.5 \%$, $338 / 508)$, of $\mathrm{HBCAb}[16]$ in DLBCL patients suggests a basis of HBV infection in this kind of lymphoma and an association between HBV and DLBCL.

The HBsAg prevalence in NHL was compared with the prevalence $(7.2 \%)[5,16]$ in the Chinese population by $\chi^{2}$ tests. The rate of HBsAg-positive serum was only significantly increased in B-cell NHL, especially in DLBCL (Table 1). There was no definite difference in the rate of HBsAg positivity in other types of lymphoma, indicating that B-cell NHL in particular, DLBCL may be related to HBV infection.

By analyzing the retrospective data of DLBCL, it was found that there were differences in the positivity rate of HBsAg at different stages of DLBCL (Table 2). In addition, there was a positive correlation between serum HBsAg positivity rate and DLBCL stage with a higher positivity rate in DLBCL patients with advanced stage III and IV disease $(P=0.041)$.

\section{HBV can directly infect lymphocytes in vitro}

Pfeiffer cells and PBMCs from a cohort of cases were chosen for infection experiments in vitro. The criterion for defining "capable infection" is the successful detection of HBV antigen and nucleic acid in lymphocytes. After HBV infection of these cells for $24 \mathrm{~h}$, intracellular $\mathrm{HBV}$ antigen was able to be detected by confocal microscopy of $\mathrm{HBx}$ protein staining in infected lymphocytes (Fig. 1). When nucleic acid was extracted from cells and amplified by PCR, intracellular HBV nucleic acid was also found (Fig. 1). This experiment indicates that HBV can infect B lymphocytes in vitro, intimating the possibility of HBV induced development of lymphoma genesis via directly infection.

\section{HBV-infected cancer cells is found in situ}

The results of immunohistochemistry illustrated that HBV antigen, especially $\mathrm{HBx}$ protein, was strongly expressed in DLBCL patients with serum HBsAg positivity (Fig. 2). There were fifteen tissue 

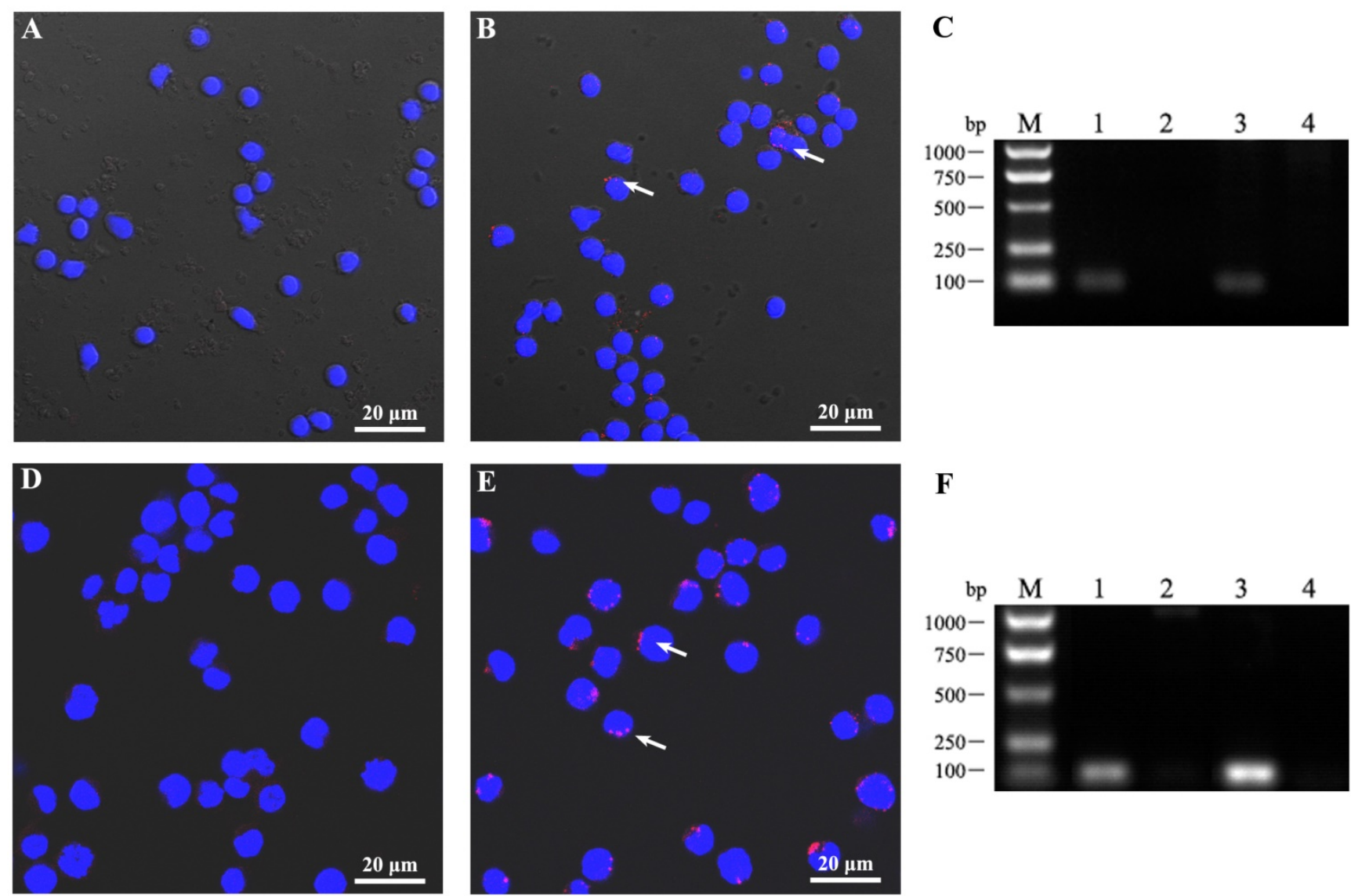

$\mathbf{F}$

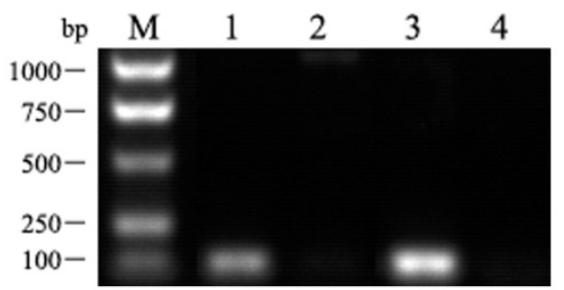

Figure 1. HBV can infect lymphocytes in vitro. (A-C) PBMCs and (D-F) the DLBCL Pfeiffer cell line were infected by HBV $(A, D)$ and a matched negative control $(B, E)$ with $\mathrm{MOI}=10$. After infection for $24 \mathrm{~h}$, the cells were collected and washed by centrifugation. (A, B, D, E) Following fixation and permeation, HBV anti-human HBx monoclonal antibody and a TRITC labeled secondary antibody was used to detect HBV by confocal microscopy and cells were stained with DAPI. (C, F) Cellular DNA was extracted and total HBV DNA was detected by PCR (fragment of 92bp). Lane 1, HBV-positive control; Lane 2, HBV-negative control; Lanes 3 and 4, cells infected for $24 \mathrm{~h}$ by HBV-positive (lane 3) or -negative (lane 4) serum. These data were expressed from at least three individual experiments.

specimens from DLBCL patients with ten serum HBsAg positivity and five negativity. The $\mathrm{HBx}$ antigen could be detected in all HBsAg-positive samples, and was strongly increased compared to that in HBsAg-negative ones according to IRS $(P<0.001)$. This finding of HBV infection in DLBCL tissue in situ shows that HBV was able to infect B lymphocytes thus indicating an association between HBV and lymphoma formation.

HBV DNA was also found in three of ten tissue samples from HBsAg-positive DLBCL patients suggesting the possibility of long-term $\mathrm{HBV}$ retention or integration (Fig. 2D).

\section{HBV infection status influences the therapeutic efficacy in DLBCL patients}

Since HBV could successfully infect lymphocytes, we next explored the clinical significance of this infection. Of the DLBCL patients in this study, $92.9 \%(472 / 508)$ underwent standard chemotherapy based on the first-line regimen of CHOP (cyclophosphamide, hydroxydaunorubicin, oncovin, and prednisone). Of these patients, $81.8 \%$ $(386 / 472)$ were also treated with rituximab within the standard chemotherapy, but there was no difference between the HBsAg groups $(76.1 \%(86 / 113) \mathrm{HBsAg}$ positive vs. $83.6 \%(300 / 359)$ HBsAg negative, $P>0.05)$. Based on these similar chemotherapy regimens, ordinal logistic regression exhibited a significant difference in therapeutic effect on individual factors of DLBCL stage or HBsAg status (Table 3). HBsAg-positive DLBCL patients had a worse therapeutic outcome of at least one grade than HBsAg-negative patients with an odds ratio (OR) of 3.04 (95\% confidence interval, 2.00-4.62). As the effect of staging grade on the prognosis of DLBCL was removed, the sensitivity to chemotherapy of HBsAg-positive patients was significantly lower in each stage, especially in patients with early-stage DLBCL (Table 3). Therefore, HBV positivity is an independent factor that is not conducive to DLBCL chemotherapy. This retrospective study suggests our important role of $\mathrm{HBV}$ in DLBCL, which requires close clinical monitoring and active intervention. 

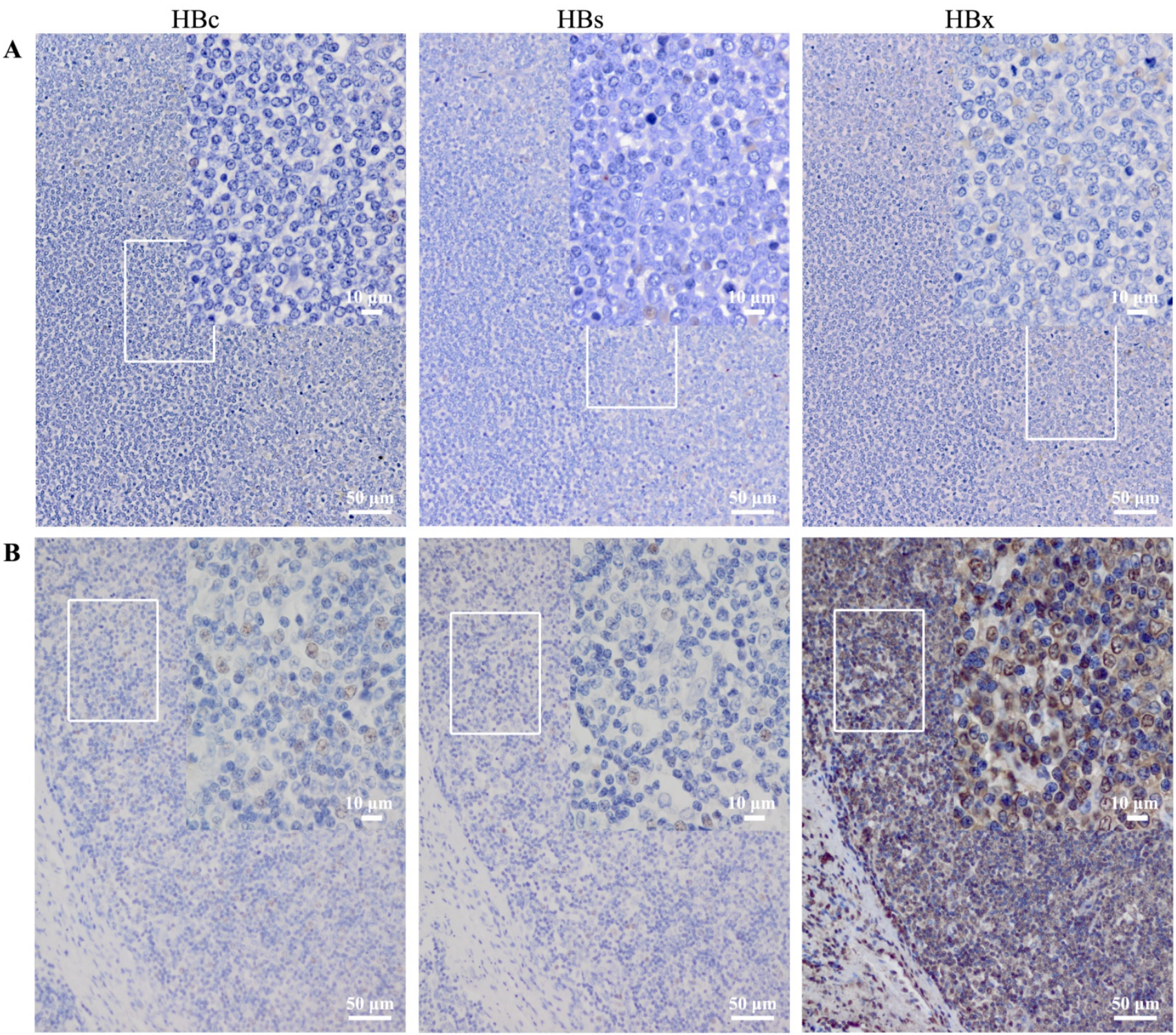

C

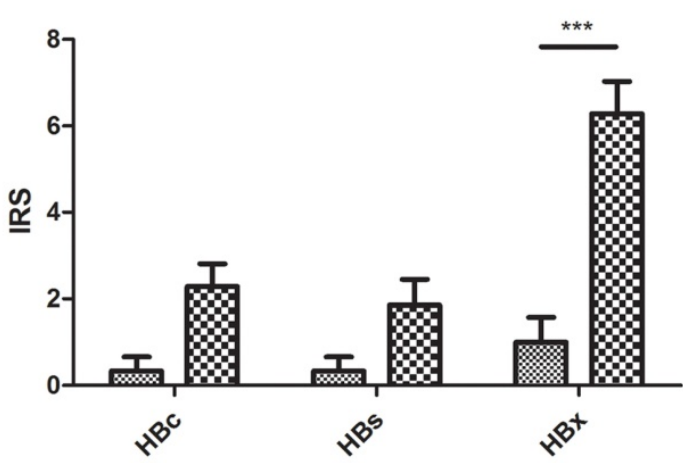

D

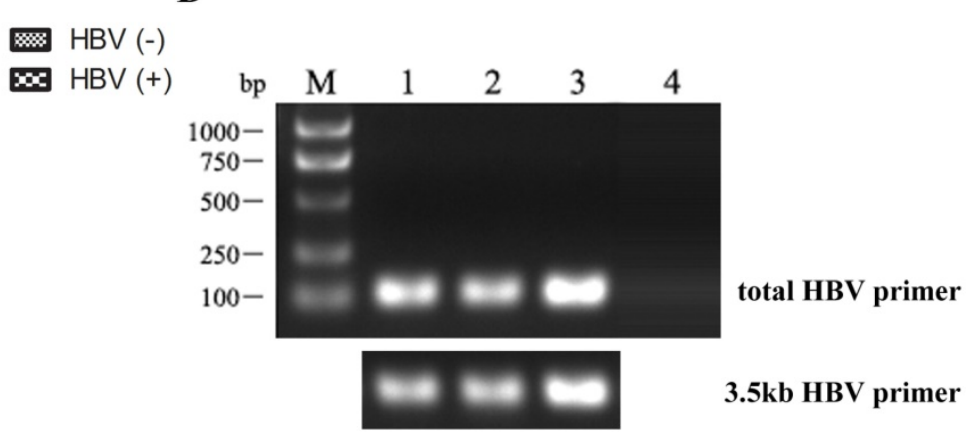

Figure 2. $\mathrm{HBV}$ was detected in DLBCL in situ. Anti-HBc, -HBs, and -HBx antibodies were used to detect the HBV antigen in several lymphoma tissue sections by immunohistochemistry. (A) Lymph node tissue from a DLBCL patient with $\mathrm{HBV}$ antigen-negative serum; (B) Patient with $\mathrm{HBs} A$ g-positive serum (> $250 \mathrm{IU} / \mathrm{mL}$ ) and HBV DNA-positive serum $\left(5.2 \times 10^{3} \mathrm{IU} / \mathrm{mL}\right)$; (C) IRS of immunohistochemistry from five serum HBV antigen-negative and ten HBV antigen-positive patients. The scores are expressed as the mean \pm standard deviation and statistics were carried out by one-way ANOVA, ***P $<0.001 ;(D)$ DNA was extracted from $D L B C L$ paraffin tissue, and HBV DNA was detected by PCR using total-HBV or 3.5kb-HBV DNA primers. DNA in lanes 1 to 3 were extracted from DLBCL tissues of $\mathrm{HBV}$-positive serum and lane 4 was from that of HBV-negative serum. 
Table 3. Effect of serum $\mathrm{HBsAg}$ on the therapeutic efficacy in various DLBCL stage.

\begin{tabular}{|c|c|c|c|c|c|c|c|}
\hline \multirow[t]{2}{*}{ Factors } & & \multicolumn{4}{|c|}{ Therapeutic Efficacy } & \multirow[t]{2}{*}{$P$ value } & \multirow[t]{2}{*}{ OR $(95 \% \mathrm{CI})$} \\
\hline & & CR & PR & SD & PD & & \\
\hline \multicolumn{8}{|c|}{ HBsAg Status } \\
\hline & Negative $(n=359)$ & 220 & 96 & 17 & 26 & $<0.001$ & 1 \\
\hline & Positive $(n=113)$ & 31 & 57 & 12 & 13 & & $3.04(2.00 \sim 4.62)$ \\
\hline DLBCL & HBsAg & & & & & & \\
\hline Stage & Status & & & & & & \\
\hline \multirow[t]{2}{*}{ I } & Negative $(n=88)$ & 73 & 14 & 0 & 1 & 0.003 & 1 \\
\hline & Positive $(n=25)$ & 13 & 12 & 0 & 0 & & $4.28(1.64 \sim 11.1)$ \\
\hline \multirow[t]{2}{*}{ II } & Negative $(n=135)$ & 88 & 39 & 4 & 4 & 0.007 & 1 \\
\hline & Positive $(n=29)$ & 10 & 17 & 0 & 2 & & $2.97(1.36 \sim 6.53)$ \\
\hline \multirow[t]{2}{*}{ III } & Negative $(n=55)$ & 24 & 22 & 5 & 4 & 0.011 & 1 \\
\hline & Positive $(n=30)$ & 5 & 15 & 6 & 4 & & $3.05(1.29 \sim 7.19)$ \\
\hline \multirow[t]{2}{*}{ IV } & Negative $(n=81)$ & 35 & 21 & 8 & 17 & 0.028 & 1 \\
\hline & Positive $(n=29)$ & 3 & 13 & 6 & 7 & & $2.39(1.10 \sim 5.22)$ \\
\hline
\end{tabular}

Ordinal logistic regression was introduced to access the factors in therapeutic efficacy of DLBCL. Effect of serum HBsAg positivity on the evaluation of therapeutic efficacy was also compared in separated DLBCL stage. All patients undergone $\mathrm{CHOP}$ regimen were evaluated in statistics.

Therapeutic efficacy was divided into 4 grade, such as CR (complete remission), PR (partial remission), SD (stable disease), and PD (progression disease).

OR: odds ratio, CI: confidence interval.

\section{Discussion}

In this research, we performed a retrospective study to analyze the clinical characteristics of DLBCL patients with $\mathrm{HBV}$ infection. Almost all HBV related lymphomas are of B-cell origin, comprising a heterogeneous group including an aggressive clinical course with a poor therapeutic effect of traditionally tolerated chemotherapy in DLBCL (Tables 1-3). Our clinical studies support a correlation between HBV infection and DLBCL progression, indicating that HBV may play a key role in the development of B-cell NHL. Dalia et al also demonstrated that there was an increased odds ratio of 2.24 for developing DLBCL in high HBV prevalence countries [17]. These clinical findings highlight the further study on latent biological mechanisms responsible for lymphomagenesis and progression in patients with HBV infection.

DLBCL is HBV-defining conditions including HBx strongly expression and HBV DNA stable intracellular existence (Fig. 2). These findings in HBsAg-positive DLBCL patients were consistent with the significant increase of $\mathrm{HBx}$ in hepatocellular carcinoma (HCC) induced by stable HBV integration $[18,19]$. The integrated $H B x$ controls the level of HBV replication and plays a critical role in HCC [20, 21]. It interacts with CREBBP, BCL2, and other molecules, causing changes in cell cycle, apoptosis, DNA damage repair, and other phenotypes with a significant difference compared to non-HBV induced liver cancer [22-24]. In the pathogenesis of DLBCL, about $32 \%$ of the DLBCL patients also have CREBBP inactivation and in $35 \%$ of DLBCL-GCB subtypes exist BCL2 ectopic expression [25, 26]. The pathogenesis of DLBCL appears consistent with the HCC pathogenesis by $\mathrm{HBx}$, and so HBV-infected lymphocytes may also lead to the development of lymphoma through the corresponding pathway. However, this hypothesis requires further studies on the function of $\mathrm{HBx}$, in particular on the effect on chemotherapy efficacy, which was different in distinct HBV infection status of DLBCL patients.

Therefore, HBV infection may be one of the risk factors for developing DLBCL. That HBV can infect B lymphocytes highlights the mechanisms involved in their pathogenesis (Fig. 1). HBV has been found in PBMC in vivo [11], and our HBV can infect PBMC in vitro, which suggests that $\mathrm{HBV}$ infection of $\mathrm{B}$ lymphocytes before tumorigenesis. However, the traditional HBV receptor is not expressed on B lymphocytes [13]. Appropriate protein and nucleic acid technology may be used to further screen and verify the related receptors for HBV infection [27].

In summary, HBV can infect B lymphocytes and may be related to the development of DLBCL. However, there is still disputed in the clinical need for DLBCL susceptible population to use anti-HBV preventive treatment. Discovery of the phagocytic pathway and $\mathrm{HBx}$ function inducing DLBCL development remains our further study for persuasive treatment strategies.

\section{Acknowledgements}

This work was supported in part by the Research Project of Shanghai Municipal Commission of Health and Family Planning (grant no. 20164Y0053), and the National Natural Science Foundation of China (grant no. 81572552). We gratefully acknowledge the Department of Pathogen Biology, Shanghai Medical College, Fudan University for experimental virus preparation and for providing antibodies.

\section{Abbreviations}

HBV: hepatitis B virus; DLBCL: Diffuse large B-cell lymphoma; NHL: non-Hodgkin lymphoma; HBsAg: hepatitis B surface antigen; HBsAb: hepatitis $B$ surface antibody; $\mathrm{HBcAb}$ : hepatitis B core antibody; HBeAg: hepatitis B e antigen; HBeAb: hepatitis B e antibody; HBx: hepatitis $\mathrm{B} \times$ protein; PBMCs: peripheral blood mononuclear cells; IHC: immunohistochemistry; IRS: immunoreactive score; MOI: multiplicity of infection; PCR: polymerase chain reaction; OR: odds ratio; HCC: hepatocellular carcinoma.

\section{Competing Interests}

The authors have declared that no competing interest exists. 


\section{References}

1. Siegel RL, Miller KD, Jemal A. Cancer Statistics, 2017. CA: a cancer journal for clinicians. 2017; 67: 7-30.

2. Perry AM, Diebold J, Nathwani BN, MacLennan KA, Muller-Hermelink HK, Bast M, et al. Non-Hodgkin lymphoma in the Far East: review of 730 cases from the international non-Hodgkin lymphoma classification project. Annals of hematology. 2016; 95: 245-51.

3. Arredouani MS, Bhasin MK, Sage DR, Dunn LK, Gill MB, Agnani D, et al. Analysis of host gene expression changes reveals distinct roles for the cytoplasmic domain of the Epstein-Barr virus receptor/CD21 in B-cell maturation, activation, and initiation of virus infection. Journal of virology. 2014; 88: 5559-77.

4. Tasleem S, Sood GK. Hepatitis C Associated B-cell Non-Hodgkin Lymphoma: Clinical Features and the Role of Antiviral Therapy. Journal of clinical and translational hepatology. 2015; 3: 134-9.

5. Liang X, Bi S, Yang W, Wang L, Cui G, Cui F, et al. Reprint of: Epidemiological serosurvey of Hepatitis B in China--declining HBV prevalence due to Hepatitis B vaccination. Vaccine. 2013; 31 Suppl 9: J21-8.

6. Deng $\mathrm{L}$, Song $\mathrm{Y}$, Young $\mathrm{KH}, \mathrm{Hu} \mathrm{S}$, Ding $\mathrm{N}$, Song $\mathrm{W}$, et al. Hepatitis $\mathrm{B}$ virus-associated diffuse large B-cell lymphoma: unique clinical features, poor outcome, and hepatitis B surface antigen-driven origin. Oncotarget. 2015; 6: 25061-75.

7. Law MF, Lai HK, Chan HN, Ha CY, Ng C, Yeung YM, et al. The impact of hepatitis $\mathrm{B}$ virus (HBV) infection on clinical outcomes of patients with diffuse large B-cell lymphoma. European journal of cancer care. 2015; 24: 117-24.

8. Wang $\mathrm{K}$, Yang H, He W, Xia Y, Xia Z, Li S, et al. Association between extranodal natural killer/T-cell lymphoma and hepatitis B viral infection: a case-control study. Journal of Cancer. 2017; 8: 2676-83.

9. Evens AM, Jovanovic BD, Su YC, Raisch DW, Ganger D, Belknap SM, et al. Rituximab-associated hepatitis B virus (HBV) reactivation in lymphoproliferative diseases: meta-analysis and examination of FDA safety reports. Annals of oncology : official journal of the European Society for Medical Oncology / ESMO. 2011; 22: 1170-80.

10. Dalia S, Suleiman Y, Croy DW, Sokol L. Association of Lymphomagenesis and the Reactivation of Hepatitis B Virus in Non-Hodgkin Lymphoma. Cancer control : journal of the Moffitt Cancer Center. 2015; 22: 360-5.

11. Cabrerizo M, Bartolome J, Caramelo C, Barril G, Carreno V. Molecular analysis of hepatitis B virus DNA in serum and peripheral blood mononuclear cells from hepatitis B surface antigen-negative cases. Hepatology. 2000; 32: 116-23.

12. Loggi E, Gamal N, Bihl F, Bernardi M, Andreone P. Adaptive response in hepatitis B virus infection. Journal of viral hepatitis. 2014; 21: 305-13.

13. Yan H, Zhong G, Xu G, He W, Jing Z, Gao Z, et al. Sodium taurocholate cotransporting polypeptide is a functional receptor for human hepatitis $B$ and D virus. eLife. 2012; 1: e00049.

14. Wei L, Shen $\mathrm{Z}$, Zhao $\mathrm{X}, \mathrm{Wu} \mathrm{Y}$, Liu $\mathrm{W}$, Zhang J, et al. A broadly reactive monoclonal antibody detects multiple genotypes of hepatitis $B$ virus $X$ protein. Archives of Virology. 2014; 159: 2731-5.

15. Halon A, Donizy P, Surowiak P, Matkowski R. ERM/Rho protein expression in ductal breast cancer: a 15 year follow-up. Cellular Oncology. 2013; 36: 181-90.

16. Yong Hao G, Da Xing F, Jin X, Xiu Hong F, Pu Mei D, Jun L, et al. The prevalence of hepatitis $B$ infection in central China: An adult population-based serological survey of a large sample size. Journal of medical virology. 2017; 89: 450-7.

17. Dalia S, Chavez J, Castillo JJ, Sokol L. Hepatitis B infection increases the risk of non-Hodgkin lymphoma: a meta-analysis of observational studies. Leukemia research. 2013; 37: 1107-15.

18. Sung WK, Zheng H, Li S, Chen R, Liu X, Li Y, et al. Genome-wide survey of recurrent HBV integration in hepatocellular carcinoma. Nature genetics. 2012; 44: 765-9.

19. Tarocchi M, Polvani S, Marroncini G, Galli A. Molecular mechanism of hepatitis B virus-induced hepatocarcinogenesis. World journal of gastroenterology. 2014; 20: 11630-40.

20. Slagle BL, Andrisani OM, Bouchard MJ, Lee CG, Ou JH, Siddiqui A. Technical standards for hepatitis B virus X protein (HBx) research. Hepatology. 2015; 61: 1416-24.

21. Benhenda S, Cougot D, Buendia M-A, Neuveut C. Chapter 4 Hepatitis B Virus X Protein. 2009; 103: 75-109.

22. Guerrieri F, Belloni L, Pediconi N Levrero M. Molecular mechanisms of HBV-associated hepatocarcinogenesis. Seminars in liver disease. 2013; 33: 147-56.

23. Geng X, Harry BL, Zhou Q, Skeen-Gaar RR, Ge X, Lee ES, et al. Hepatitis B virus $\mathrm{X}$ protein targets the $\mathrm{Bcl}-2$ protein $\mathrm{CED}-9$ to induce intracellular $\mathrm{Ca} 2+$ increase and cell death in Caenorhabditis elegans. Proceedings of the National Academy of Sciences of the United States of America. 2012; 109: 18465-70.

24. Ringelhan M, O'Connor T, Protzer U, Heikenwalder $\mathrm{M}$. The direct and indirect roles of HBV in liver cancer: prospective markers for HCC screening and potential therapeutic targets. The Journal of pathology. 2015; 235: 355-67.

25. Basso K, Dalla-Favera R. Germinal centres and B cell lymphomagenesis. Nature reviews Immunology. 2015; 15: 172-84.

26. Pasqualucci L, Dalla-Favera R. SnapShot: diffuse large B cell lymphoma. Cancer cell. 2014; 25: 132- e1.
27. Psathas JN, Doonan PI, Raman P, Freedman BD, Minn AJ Thomas-Tikhonenko A. The Myc-miR-17-92 axis amplifies B-cell receptor signaling via inhibition of ITIM proteins: a novel lymphomagenic feed-forward loop. Blood. 2013; 122: 4220-9. 